\title{
The Role of Trust in the Transition from Traditional to Electronic B2B Relationships in Agri-Food Chains
}

\begin{abstract}
E-business adoption rates in the agri-food sector are rather low, despite the fact that technical barriers have been mostly overcome during the last years and a large number of sophisticated offers are available. However, concerns about trust seem to impede the development of electronic relationships in the agri-food chains as trust is of particular importance in any exchange of agri-food products along the value chain. Drawing on existing research, characteristics and dimensions of trust are initially identified both in traditional and in electronic B2B relationships and a typology of trust is proposed. The aim of the paper is to provide an overview of the implementation and use of trust elements that e-commerce offers dedicated to agri-food sector. This assessment will show the current situation and discuss gaps for further improvement with the objective to facilitate the uptake of e-commerce in agri-food chains.
\end{abstract}

Keywords: B2B relationships, trust typology, electronic trust, agri-food chains

\section{Introduction}

The Information and Communication Technology (ICT) revolution and the introduction of ebusiness applications in the mid-nineties brought companies in front of an excellent opportunity to facilitate and improve their business processes or even to build completely new business models. While in many business environments ICT and e-business have been an established driver of change and a source of competitive advantage, this was not the case in the agri-food industry. On the contrary, e-business adoption rates have been rather slow despite the potential benefits in the agri-food sector as opposed to other sectors of the economy (European Commission, 2007, see also Fritz et al. 2008 for an overview of e-business offers for the agri-food sector), and despite the fact that in comparison to the early stages of e-business, technical barriers are no longer considered as critical in its adoption. Indeed, a recent survey conducted by the "European ebusiness watch", in ten different business industries (Food \& Beverages industry was included) regarding e-business adoption, revealed that technical barriers were not perceived by companies as important as for example the non technical barriers (e.g. cost, firm's size) (European Commission, 2007). Of course, at this point distinguishing between developed and developing countries is important, as especially in less developed countries their e-readiness is low and technical issues still constitute a fundamental barrier in the e-business adoption process (Wresch, 2003; EIU, 2007).

The approach followed in this paper regarding e-business is the one by Brown and Lockett (2004). According to them: "E-business includes a number of applications that vary in complexity and could be defined as the use of the Internet or any other electronic medium for the execution of transactions, the support of business processes and the improvement of collaboration opportunities among entities". Therefore, in this paper, in an effort to avoid generalizations, emphasis is given on one specific application of e-business, the application of e-commerce. In addition, following the distinction proposed by Yamin and Sinkovic (2006), it should be noted that the paper seeds lights in a specific sector, the agri-food sector, where products and services are not digitalised, and only part of the cross-border value chain can be created online.

It is sometimes argued that e-commerce should lead to disintermediation and that through e-commerce, producers would be able to sell their products directly to customers, bypassing intermediate distributors, and thus significantly reducing transaction costs (Wen, 2007). Unfortunately, while it is always possible to eliminate intermediaries, it is not possible to eliminate the market functions they perform: adding form, time, place, information, and possession utility to the goods that are made available on the market, making them able to satisfy the customer's needs and wants (Dixon, 1990; Shaw, 1991). Therefore, rather than bringing disintermediation, e-commerce may change the nature and the role of the intermediaries, selecting those who are able to take advantage of the new available technologies for becoming 
more efficient in providing the services required by the market (Delfmann et al. 2002). ICT is able to promote new organizational forms on the markets, changing the way both transactions are executed and cooperation/relationships among enterprises are established and implemented. Building market relationships basically means sharing information and fostering mutual cooperation rather than just doing transactions. An electronic marketplace (EMP) may thus represent a new environment in which intermediaries provide services that did not exist before (Rossignoli, 2009) and where supply chain operations management (Zhang and Bhattacharyya, 2009) as well as relationships management are heavily affected by the available e-business applications. In an international B2B framework, Yamin and Sinkovics (2006) hypothesize that online experience may reduce psychic distance, although they warn that a so called 'virtuality trap' may actually lead to lower market performance. This may happen because, in markets that are perceived more psychically close, managers may assume that investing resources to learn about the market is unnecessary, thus failing to take into account subtle but performancehindering cultural differences.

A crucial barrier towards the uptake of e-business applications, e-commerce in particular, enabling the access to the EMP that needs further attention is trust (Ratnasingam, 2005). In traditional business relationships the role of inter-organizational trust has received much attention and has been a well explored area. In electronic business relationships however, the transformation of business activity requires companies to consider alternative ways and approaches of trust formation due to a number of specific characteristics. For example, time in e$\mathrm{B} 2 \mathrm{~B}$ relationships is very important as electronic transactions are often subject to time pressures and restrictions, since in many cases e-B2B relationships are short-term and project oriented. Uncertainty (due to impersonal nature of the on-line environment) and information asymmetry (due to the inability to judge product quality prior to purchase) are two additional barriers (Furnell and Carweni, 1999; Agarwal and Shankar, 2003).

Particularly, in the agri-food sector the role of trust is of crucial importance as many aspects of food quality are process characteristics and may be difficult to scrutinize at the raw, intermediate or end product (Batt, 2003, Fischer et al., 2007). As a consequence, procurement decisions of agri-food companies require the presence of trust as decision variable (Hornibrook, Fearne, 2003). This is particularly relevant in a first transaction with a new supplier where prior experience does not yet exist. For the agri-food sector, the linkage between information and communication technology driven opportunities and the issue of trust is of particular importance due to the challenges in communicating food quality issues across the food supply chain.

Research on trust has been focusing so far in the business to customer (B2C) part of ebusiness, rather than business to business (B2B) part, despite the fact that the later is the most important for companies (McGaughey, 2002; European Commission, 2007). Drawing on existing research, characteristics and dimensions of trust are initially identified both in traditional and in electronic B2B relationships and a typology of trust is proposed. The aim of the analysis is to provide an overview of the current status of the implementation and use of trust elements in the available e-business landscape dedicated to the agri-food sector. This will result in increased understanding of the gaps and requirements regarding the creation of trust needed to better design EMP-enabling applications tailored to the needs of the agri-food sector.

\section{Overview or current e-commerce in agri-food chains and the issue of trust}

In the agri-food sector, a variety of different e-business tools available to companies has emerged and a proper e-commerce infrastructure has evolved in food supply networks. Different types of e-business platforms either support transactions along the entire agri-food chain or act in spot market environments, are specialized in supporting existing business relationships at a specific stage of the agri-food chain, mediate particular agri-food product lines and focus on agriculture related segments of the chain, or are driven by agri-food players and particularly adapted to their participants' requirements. Furthermore, there is empirical evidence that cooperation initiatives between platforms evolve (Fritz et al. 2004). Cooperation initiatives focus on the joint use of trading functionalities and the development of standards regarding product descriptions and 
platform transactions. Cooperation initiatives result in the emergence of networks of interconnected platforms. It could be shown that existing collaborations between platforms already relate to a platform infrastructure that could cover the marketing processes of a complete agri-food value chain and network (Fritz et al. 2008; Briz et al. 2008). The availability of such e-business solutions offers potentials for the coordination of transactions across the stages of a supply network (Geoffrion and Krishnan, 2001; Swaminathan and Tayur, 2003).

Potentials for improved coordination are particularly interesting in the agri-food sector where market dynamics, global markets and fragmentation prevail (Hausen et al., 2006). However, adoption of e-business transaction support by businesses is low, in particular by small and medium sized enterprises (SMEs) in the agri-food sector (European Commission, 2005). The model of transaction decision determinants assists in understanding the low adoption rate. Transaction decisions are the result of an unstructured, fuzzy reasoning process (Turban, 1988) taking into account decision variables from (Tan and Thoen, 2002):

- the transaction situation with potential gains and advantages for the company as well as risks or losses regarding the outcome,

- the external transaction environment creating trust and providing control mechanisms or hazards and risks. This is of particular importance in the agri-food sector where the creation of trust and provision of control opportunities is supported by quality certificates (Krieger, 2008).

In a decision situation such as a transaction, the relationship between risks, gain, trust and control as influencing factors is highly complex (Tan and Thoen, 2002). In particular, trust and control may be considered as complementary and reciprocally influencing constructs and not just substitutes for each other (Gallivan and Depledge, 2003).

The introduction of electronic transaction support changes the transaction setting that is the basis for the transaction decision. Potential efficiency improvements in transaction processes and coordination potentials could affect the potential gains of a transaction situation. However, in e-business perceived risks could rise as electronic transaction means might be perceived as anonymous, providing less availability of control and safeguards (Patton and Josang, 2004). Trust generation applied in the traditional way of doing business such as personal contacts or direct product or production site inspection could be missing. As a consequence, the perceived level of transaction trust and the transaction trust threshold as determinants for the transaction decision could be changed in electronic transaction settings.

\section{Towards a typology of trust in traditional B2B relationships in agri-food chains}

Formation of trust in traditional business relationships has been always associated with the business to business relationship lifecycle, particularly with the initial stages where trust is seen as most critical to develop and where experiences with a business partner have not yet been made (Wilson, 1995). The emphasis of the elements for trust generation in this paper is therefore placed on the pre-relationship stages where particular challenges exist.

\subsection{The process of buying from a new supplier}

Company networks in the agri-food sector tend to be very stable. But in some sectors new suppliers are sought on a more regular basis (Menard and Klein, 2004). This has recently been the case in the organic agri-food sector where growing market share in Europe has forced food retailers to look for new suppliers, especially of produce and cereal products (Goessler, 2007, ISMEA, 2008, Soil Association, 2007). The decision to buy from a new supplier takes a number of steps. A buyer at a Dutch food specialties wholesale company who is always on the lookout for new procurement opportunities follows the following steps:

- scout market / fairs

- sample taking and testing; if ok then

- check on the firm (e.g. certificates or audit); if ok then

- make specifications for the product; if ok then 
- agree on price, quantities, dates; if ok then

- buy

This is just one example. Which steps a buyer takes, and in what sequence, depends. The function of the steps is to find acceptable products and to eliminate risks. Which risks there are depends upon product (for example: is it a specialty or a commodity? Are health risks severe or not?), upon seller characteristics (reputation known?), upon market environments (from known region or country?). The sequence depicted here zooms in from the external transaction environment (Tan and Thoen, 2002) to the actual transaction. But variation between sectors, between market segments, and between individuals is considerable.

\subsection{Trust and risk}

The issue of trust has been researched "in extenso" in many fields, which testifies to its importance. We do not intend to revisit the body of research here. Reviews are given in Hofstede (2006), Fritz and Fischer (2007), Fritz and Canavari (2008) and Hofstede et al (forthcoming). Definitions given depend upon the angle of research, the discipline, and the cultural background of the researchers, and one single catchall definition is not to be expected. For instance, Dutch author Nooteboom (2002) distinguishes trust from control. To accommodate those who say 'trust is good, but control is better' Hofstede (2006) uses the terms intrinsic trust and enforced trust, where enforced trust is trust backed up by the possibility for punishment in case of breach of trust.

Trust, by any definition, involves an expectation by a buyer that a seller will act in that buyer's best interest. As illustrated in the previous section, it can have different objects that vary in scope: one can trust the product, the seller, and the institutional environment. The latter would only become salient in the cases of purchases from countries of which one doubt the legal enforcement opportunities. Our working definition should cater for small companies expected to rely on good personal relationships, for whom enforcement is not an attractive option and who operate in networks where personal ties and reputation are important. But a transition to professionalized environments in which larger firms operated is happening for these companies. We therefore need to include the elements given in table 1 below, which ranges throughout the spectrum from trust to control and from relational to anonymous.

\section{Insert Table 1}

The boundaries between boxes in the table are not always sharp. For instance, reputation is a mechanism that is very much internalized in human institutions and practices, so that it can make intrinsic and enforced trust coincide. We exchange news, we gossip, we introduce friends to each other. These activities build informal networks of intrinsic trust. But the cumulative effect is to enforce trust in any business environment where a good reputation is valuable. It is clear from the summary discussion above that one can expect different sources of trust to be prominent depending upon which risks are perceived to be important.

\subsection{A typology of trust elements}

Based on the analysis presented here, the authors decided that a tool for analysing trust requirements was called for that would be generic across sectors and business environments. $A$ process of trial and intensive discussions among researchers led to a first version. The methodology adopted to develop the trust typology integrates a desk research literature study and a qualitative survey of food industry companies. Literature review about inter-organizational trust lays a foundation for designing a draft typology based on previous studies, with special attention paid to the influence of culture. This draft typology was fine-tuned and tested for face validity in a round of 18 qualitative in-depth interviews with key informants in four industries (fresh fruit, grain, meat and olive oil) and in various countries (Germany, Greece, Italy, the 
Netherlands, and Spain). This led to the typology of figure 1. The process and typology are described in more detail in e-Trust (2007) and Hofstede et al. (forthcoming).

\author{
Insert Figure 1
}

The typology takes the perspective of a buyer, because a buyer faces information asymmetry about the product. In accordance with the description about the buying process in section 3.1, level 1 is divided according to scope. It includes the product per se, the seller, and the wider market environment. Level 2 refines these three sources of trust. Level 3 is sector-, country -, and product-dependent. Specifics are presented in the appendix.

\title{
4. From Trust to e-Trust for agri-food chains: Examining the typology in an electronic context
}

\subsection{Research design and procedure}

In this section the proposed trust typology is applied to the electronic context. The analysis derives from a combination of desk and empirical research. Building on the typology, we adopt a case-study research methodology that is defined by Yin (2003) as "an empirical inquiry that investigates a contemporary phenomenon within its real-life context". The technically distinctive trait of a case study inquiry is that there will be many more variables of interest than data points, and "as one result relies on multiple sources of evidence, with data needing to converge in a triangulating fashion, and as another result benefits from the prior development of theoretical propositions to guide data collection and analysis" (Yin, 2003).

Trust elements in sixty out of about one hundred e-marketplaces operating in the agrifood sector have been analyzed on-line through the direct observation of websites performed in summer 2008. Since we are not simply measuring quantitative data, this social research method suffers of a potential problem of subjectivity introduced by the researcher who performs the interpretation of the collected information. Therefore, given the inherently subjective method of observation adopted, the sample of marketplaces was split into two sub-samples that have been independently analyzed by two researchers. After finalizing the analysis of their sample halves, each researcher reviewed the analysis of the other one. This method was used to limit the level of subjectivity in the analysis.

The information deriving from direct observation of the 60 cases observed in the realworld situation were complemented by face-to-face and telephone qualitative interviews with 16 key players in the food industry, aimed at testing the validity of the comparisons between trust elements and their implementation in real world e-marketplace websites. The equivalence issue (Sinkovics et al., 2005), which may arise when respondents with different cultural background are asked to interpret a complex construct, has been coped with using the trust typology, which has proven to be a precious guidance for the interviewers and in our opinion worked as an effective standardisation tool. A summary of the main findings of our analysis is presented here following the trust typology structure.

\subsection{Empirical findings on trust creation in electronic marketplaces for agri-food products}

With respect to the product, five sub-dimensions are identified: reputation, specification, inspection, certification, and price-performance ratio. The starting point for all product information is the online product catalogue. Here, suppliers show all basic product specifications and provide links for further external information.

Product reputation: Similar to a company's online branding activities, suppliers can use their website to build the reputation of single products. Awards, for example, are mentionable attributes which can be attractively incorporated into a website. Country/area of origin is an important aspect for specific products.

Product specification: All product specifications, such as product description, purpose of use, and product details (e.g. size and colour), can be presented "easy to use" in the Web 
catalogue. Suppliers can make use of a variety of features to present their products more interactively (e.g. podcasts). A company can communicate the product's legal compliance and the specifications on the raw material's origin. Furthermore, the Internet technology and its Web link structure offer easy access to external information sources, such as the European directive on organic farming or information on prescriptive limits for fertilizer. However, additionally to the provision of information, suppliers can implement more product service oriented features, which the customers can individually use at any time (e.g. a calculator that determines the optimal combination of the single fertilizer's inputs). In the e-marketplaces analysis, product specifications is the most frequent trust object employed and it is still one of the qualifying elements, although in some cases buyers and sellers must interact directly in order to clearly assess the product characteristics.

Product inspection: Product inspection is based on face-to-face contact, i.e. it is decoupled from the online transaction. However, a visit of a company's production site and laboratories can be supported by visualizing technologies like virtual reality, even if virtual reality might not be considered as trustworthy in itself by some persons. This virtual visit can be combined with synchronous communication tools (e.g. video-conferencing) to enable the supervision of sampling and laboratory analysis. This feature is rarely applied in the e-marketplaces. A key statement regarding product inspection of German grain buyers is "We only believe what we see".

Product certification: Analogously to the presentation of information about a product's specification, suppliers can make their certificates available online. Additionally, a seller can make use of the Internet's structure to link to the websites of trusted third parties. Here, the customer can retrieve detailed information on certification criteria. Contrary to expectation, in the actual web sites there is little communication of product certification. Regarding the value of product certification for trust generation, a German buyer in the cereal sector states "Certificates are ok, but if someone wants to cheat, he cheats!"

Price / Performance ratio: Buyers use electronic auctions to dynamically negotiate prices and qualities of different offers. Overall, the broad access to information on offers increases transparency and helps a buyer to assess price / performance ratios. Some websites provide market prices as benchmark; others provide 'guarantees' about the price like a statement "at best price".

With respect to the seller, four sub-dimensions exist: capability, relationship, reliability, and reputation. As in the offline context, an online supplier has to communicate his capability and reliability and build a relationship with the customer through intensive communication. However, in the e-commerce context, a supplier has to additionally communicate his competence to run the supporting technology, while respecting privacy and security issues.

Capability of the selling company: A buyer can retrieve plenty of information about the seller's company by studying his website. On the webpage "about us", he gets to know the company's field of activity, organizational structure, goals, and size. In "terms of use", the buyer gets informed about the seller's general business practices. Furthermore, the customer learns what the seller's efforts on privacy and security are. To present the company more "personally", the supplier can make use of a podcast to let the chief executive officer (CEO) audio-visually introduce the company and its business activities and visions. With help of the podcast, the buyer can take a "tour" over the production site and see the single production processes. Furthermore, the sales team can be introduced to the buyer, and the sales team's responsibilities can be explained. The CEO can furthermore make use of the podcast to visualize the ICT infrastructure that supports the order processing. It can be shown that the technological infrastructure makes all order process activities transparent and provides the customer access to all order-related data. The company can communicate that the transparency they offer to their customers is as high as the transparency they require from their suppliers and that tracking and tracing along the production chain is ensured. After a customer has learned almost everything about the seller's company through the podcast, he can furthermore contact the seller to have a live video conversation to clarify the last open questions. After the whole communication process, the buyer is able to judge whether the seller company's business standards suit his requirements. 
Information on the company is usually available on the e-marketplaces, but the type of information is diverse and it shows different levels of depth (for instance, information on production capacity or inventory availability is rarely provided, while a generic company profile is almost always presented).

Relationship between buyer and seller: In the typology, the authors distinguish the relationship between trading individuals from the relationship between companies. The personal relationship is considered quite important in the Dutch meat and vegetable sector. One statement from an interviewee in the Dutch horticulture sector illustrates this: "Reputation of growers and experience with these growers are the most important factors to provide trust". Up until now, e-commerce suffers from a missing face-to-face interaction between individuals. However, e-commerce also offers new formats to build initial and long-term relationships. A Web blog is a very appropriate format to mix personal with business-related experiences in form of a diary. Overall, the up-to-dateness, the variety of content, and the direct association of the content with the seller help increasing the company's trustworthiness. The relationship building between the buyer's and the seller's company can be supported by the same technologies as described under Capability of the seller's company. If a seller wants to initiate a long-term relationship with a first time buyer, he can use a podcast to provide an initial idea of company's culture, to present his customer orientation, and to show his flexibility with respect to prices and delivery conditions. On several websites it is possible to establish a contact between buyers and sellers. In several cases anonymity is not allowed, although we found that two (out of sixty) e-marketplaces actively avoid the possibility of a contact as a way to better serve customers offering "guaranteed anonymity".

Reliability of the seller: Via a website, the communication can be fast and effectively streamlined to the responsible staff. Furthermore, the contact via the website offers a high degree of automation by simultaneously providing a high degree of commitment. Customers quickly have a response and a written document in their hands. Within an e-mail, the whole communication history can be recorded, and it can be made transparent who is involved in the process. Important components of the contract are price, quantity, delivery dates, and shipping instructions. Overall, the contracting (including warranties) can be as trustworthily designed in ecommerce as in traditional trade. The supplier's order tracking system provides the customer with the necessary transparency on delivery status and dates. Some e-marketplaces ascertain and guarantee financial aspects of the transaction or reliable logistic service with the help of third party logistics providers.

Financial situation: The financial situation of a supplier as a guarantee to fulfil the order should generally be made available online as part of the company's profile.

Reputation of the seller: Overall, the Internet is crucial for the communication of the supplier's reputation. On the one hand, suppliers actively communicate their reputation via their own website by publishing references of third parties and customers. Suppliers depend also upon other websites, where the online community rates suppliers' performances. Potential buyers also derive their perceptions of a supplier's reputation from other community platforms.

With respect to the market environment, four sub-dimensions are identified: private control institutions, informal institutions, public legal institutions and reputation.

Private control institutions: In the e-commerce context, standards for a safe trading environment are established and controlled by trusted third parties. Those trusted third parties verify if an online supplier meets specific certification criteria. The supplier can publish a third party's seal on his website to communicate his compliance to a certain standard.

Informal institutions: Informal institutions, such as the International E-Business Association (IEBA e.V.), provide general guidelines and codes of conducts to facilitate fair e-commerce. Sometimes, suppliers publish their membership in such industry associations. In many cases the ecommerce platforms themselves take the responsibility to act as informal third-party controllers of the correct executions at several stages of the transaction process.

Public legal institutions: Public legal institutions, such as the International Chamber of Commerce (ICC), fulfil the same functions as the informal institutions. The large majority of the emarketplaces analyzed refer to legal procedures as an element in their "terms of use" statement. 
In the e-marketplaces reputation is often communicated through industry association membership or endorsement, as well as when large companies participate into the emarketplace. Although not always strongly communicated, reputation of sellers is displayed through informal/non institutional ways. E-marketplaces ask sometimes their users to rate other operators, or to signal not adequate or poor service listing. The rating can be considered as a trust sign, showing a sort of real-time reputation. In some cases, ratings are assigned by the e-platform to the operators, taking into consideration their financial reliability. Sometimes these ratings appear together with operators' e-business key performance indicators (e.g. count or percentage of transactions positively concluded), and with community's comments about their approach to the platform: in case of divergence, negative trust signals can be originated.

\section{Conclusions}

This paper has presented a study on factors in a transaction contributing to the creation of trust and how these factors are communicated in an e-business environment to facilitate the adoption of e-business in agri-food networks. In particular, the proposed trust typology was then applied based on an examination of e-marketplaces dedicated to agri-food products. For example, with respect to product, critical sub-dimensions such as product inspection or product specification it seems that they are not currently communicated in the e-marketplaces examined. With respect to the seller, it is interesting to notice the differences for sub-dimensions such as Relationship between buyer and seller or reliability of the seller. For example, while in several cases anonymity was not allowed, in other cases e-marketplaces actively avoid the possibility of a contact. Finally, with respect to market environment, it was found that reputation was often communicated through the memberships in public legal, and informal or private control institutions.

A very important issue related to trust generation is the influence by culture (Seppänen et al. 2007). This is extremely important as agri-food chains are characterized to a great extent by cross-country transactions and exchanges. Culture affects risk perception and the nature of trust depends on the implicit model of relationships, which varies in the world. It can be friendly, oppositional, or instrumental. Table 1 has showed that there are various ways to create trust. The relative importance of these varies importantly along cultural lines. The $5 \mathrm{D}$ model of culture by Hofstede (Hofstede and Hofstede, 2005) can be used to indicate a few main trends in Europe. In the individualistic, egalitarian societies of North-West Europe, the institutional environment can take care of opportunity control. In hierarchical societies of the Balkans and Russia, this cannot be taken for granted, and other sources of trust are more important, such as reputation, perceived match, and in collectivistic societies also kinship. In the feminine, uncertainty tolerant societies of Scandinavia, data sharing and transparency are considered obviously beneficial for all. But in the rest of Europe, companies tend to keep their cards to them, and might be distrustful of one another as well as of legal and certification entities (Hofstede et al. 2004; Hofstede and Hofstede, 2005). But the conclusion must be that different trust generation mechanisms can be expected to be prominent in different parts of Europe. This is also in line with the work by Jean et al. (2008) which offered arguments that some cultural and country level factors can affect IT practices in a country and moderate the impact of such IT capabilities on international B2B activities.

Against this background, immediate next research steps should be to explore what is the importance allocated to each dimension and sub-dimension by company managers, procurement managers in particular, in different sectoral and cultural settings. The ultimate goal and contribution of the model will be to present what are the characteristics that procurement managers currently look for, and whether or not these trust sub-dimensions really appear in the existing agri-food e-marketplaces. If not, e-marketplace designers and companies must try either to incorporate these sub-dimensions in their marketplaces or try to communicate them more clearly. The specific nature of agricultural products is an additional element needed to be taken into consideration when examining trust formation in the sector. It is therefore interesting to identify whether or not variations in the importance of trust elements appear in the agri-food sector in different product lines or subsectors (e.g. meat, cereals, fresh produce, olive oil). 


\section{References}

Agarwal, A., Shankar, R., 2003. On-line trust building in e-enabled supply chain. Sup. Ch. Manag.: An Int. J. 8, 324-334.

Batt, P.J. 2003. Building trust between growers and market agents. Sup. Ch. Manag.: An Int. J. 8, 65-78.

Briz, J., Canavari, M., Deiters, J., Fernandez, C., Fritz, M., Hofstede, G.J., Ohliger, A., Pignatti, E., Scherhag, A., Schiefer, G., van Sprundel, G.-J., 2008. B2B trust elements in e-commerce, (unpublished), Deliverable 6 of European research project "e-Trust: Building trust for quality assurance in emerging markets in food chains", Contract No. FP6-043056.

Brown, D.H., Lockett, N., 2004. Potential of e-applications for engaging SMEs in e-business: a provider perspective, Eur. J. of Inf. Syst. 13, 21-34.

Delfmann, W., Sascha, A., Gehring, M., 2002. The impact of electronic commerce on logistics service providers. Int. J. of Phys. Distrib. \& Logist. Manag. 32, 203-222.

Dixon, D. F., 1990. Marketing as production: The development of a concept, J. Acad. Market. Sci. $18,337-343$.

EIU, 2007. The 2007 e-readiness rankings: Raising the bar, A white paper from the Economist Intelligence Unit, The Economist.

European Commission, 2007. e-Business Watch. A portrait of e-business in 10 sectors of the EU economy, $5^{\text {th }}$ Synthesis Report of the e-Business W@tch.

European Commission, 2005. e-Business Watch. ICT and Electronic Business in the Food and Beverages Industry. ICT adoption and e-business activity in 2005. Sector Report No. 01-II (September 2005). Available at: http://www.ebusinesswatch.org/resources/food/SRo1b Food_2005_web.pdf

Fischer, C., Gonzalez, M.A., Henchion, M., Leat, P. 2007. Factors influencing trust supporting mechanisms in European agri-food chains. Food Econ. 4, 40-49

Fritz, M., Fischer, C. 2007. The role of trust in European food chains: theory and empirical findings. Int. Food and Agrib. Man. Rev. 10,141-163.

Fritz, M., Canavari, M. 2008. Management of Perceived e-Business Risks in Food Supply Networks: e-Trust as Prerequisite for Supply Chain System Innovation. Agribus: An Int. J. 24. 355-368.

Fritz, M., Hausen, T., 2008. Electronic trade platforms in food networks: An analysis of emerging platform models and strategies. Journal of Inf. Tech. in Agric. 3, 26-36.

Fritz, M., Hausen, T., Schiefer, G. 2004. Developments and Development Directions of Electronic Trade Platforms in US and European Agri-Food Markets: Impact on Sector Organization. Int. Food and Agrib. Manag. Rev.7, 1-20

Furnell, S.M, Karweni, T., 1999. Security implications of electronic commerce: a survey of consumers and business. Intern. Res. 9, 372-382.

Gallivan, M.J., Depledge, G. 2003. Trust, control and the role of interorganizational systems in electronic partnerships. Inform. Syst. J. 13, 159-190.

Geoffrion, A., Krishnan, R., 2001. Prospects for operations research in the e-business era. Interfaces 31, 6-36.

Goessler, R. 2007. Ökomarkt Jahrbuch 2007 - Verkaufspreise im ökologischen Landbau. ZMP Zentrale Markt- und Preisberichtstelle, Bonn (in German).

Hausen, T., Fritz, M., Schiefer, G., 2006. Potential of electronic trading in complex supply chains: an experimental study. Int. J. of Prod. Econ. 104, 580-597.

Hofstede, G., Hofstede, G. J., 2005. Cultures and Organizations: Software of the Mind. Third Millennium Edition. New York: McGraw-Hill.

Hofstede, G. J., 2006. Intrinsic and Enforceable Trust: A Research Agenda. In Trust and Risk in Business Networks. Bonn: Universität Bonn-ILB Press, pp. 15-24.

Hofstede, G. J., Spaans, L., Schepers, H., Trienekens, J. H., Beulens, A. J. M., 2004. Hide or confide: the dilemma of transparency. den Haag: Reed Business Information.

Hofstede, G.J., Canavari, M., Fritz, M., Oosterkamp, E., Sprundel, G-J van. Towards a cross-cultural typology of trust in B2B food trade. Brit. Food J. (forthcoming)

Hornibrook, S., Fearne, A. 2003. Managing perceived risk as a marketing strategy for beef in the UK foodservice industry: Results of a case study of catering purchasers of fresh beef. Int. Food and Agrib. Manag. Rev. 6, 70-93. 
Jean, R. J. B., Sinkovics, R. R., Kim, D. 2008. Information Technology and Organizational Performance within International Business to Business Relationships - A Review and an Integrated Conceptual Framework, Int. Mark. Rev. 25, 563-583.

ISMEA. 2008. II biologico nel Bacino del Mediterraneo. Politiche, normative e mercati per un'agricoltura di qualità. www.ismea.it (in Italian)

Krieger, S. 2008. Qualitätssysteme der Agrar- und Ernährungswirtschaft - Entwicklung eines Beratungssystems zur Kosten- und Nutzenschätzung. Dr. Kovac, Hamburg (in German).

McGaughey, R.E., 2002. Benchmarking business-to-business electronic commerce, Benchm: An Int. J. 9, 471-484.

Menard, C., Klein, P., 2004. Organizational Issues in the Agri-Food Sector: Toward a Comparative Approach. Amer. J. of Agric. Econ. 86, 746-751.

Nooteboom, B., 2002. Trust: forms, foundations, functions, failures and figures. Cheltenham, UK: Edward Elgar Publishing.

Patton, M.A., Josang, A., 2004. Technologies for trust in electronic commerce. Electron. Comm. Res. 4, 9-21

Ratnasingam, P., 2005. Trust in inter-organizational exchanges: a case study in business to business electronic commerce, Decis. Support Syst. 39, 525-544.

Rossignoli, C., 2009. The contribution of transaction cost theory and other network-oriented techniques to digital markets, Inf. Syst. E-Bus. Manage. 7, 57-79.

Seppänen, S., Blomqvist, K., Sundqvist, S. 2007. Measuring inter-organizational trust-a critical review of the empirical research in 1990-2003. Ind. Mark. Manag. 36, 249-265.

Shaw, E. H., 1991. An historical analysis of the four utilities concept and its relevance for modern marketing thought. Marketing History - Its Many Dimensions, Proceedings of the $5^{\text {th }}$ Conference on Historical Analysis \& Research in Marketing, Michigan State University, East Lansing, Michigan, April 19 - 21, 1991, pp. 33-48.

Sinkovics, R. R., Penz, E., Ghauri, P. N., 2005. Analysing textual data in international marketing research. Qual. Market Res. Int. J. 8, 9-38.

Soil Association. 2007. Organic Market Report 2007. Bristol.

Swaminathan, J.M., Tayur, S.R., 2003. Models for supply chains in e-business. Manag. Scie. 49, $1387-1406$.

Tan, Y.-H., Thoen, W. 2002. Formal aspects of a generic model of trust for electronic commerce, Decis. Support Syst. 33, 233-246.

Turban, E., 1988. Decision support and expert systems: Managerial perspectives. New York: Macmillan.

Wen, W., 2007. A knowledge-based intelligent electronic commerce system for selling agricultural products, Comput. Electron Agric. 57, 33-46.

Wilson, D.T., 1995. An integrated model of buyer-seller relationships, J. Acad. Mark. Scien. 23, 335-345.

Wresch, W., 2003. Initial e-commerce efforts in nine least developed countries: A review of national infrastructure, business approaches and product selection, J. of Glob. Infor. Manag. 11, 67-79.

Yamin, M., Sinkovics, R. R. 2006. Online internationalisation, psychic distance reduction and the virtuality trap, Int. Bus. Rev. 15, 339-360.

Yin, R.K., 2003. Case study research. design and methods, $3^{\text {rd }}$ ed. Thousand Oaks, California: SAGE Publications.

Zhang, Y., Bhattacharyya, S., 2009. Analysis of B2B e-marketplaces: an operations perspective, Inf Syst E-Bus Manage, in press, doi:10.1007/s10257-008-0096-y. 


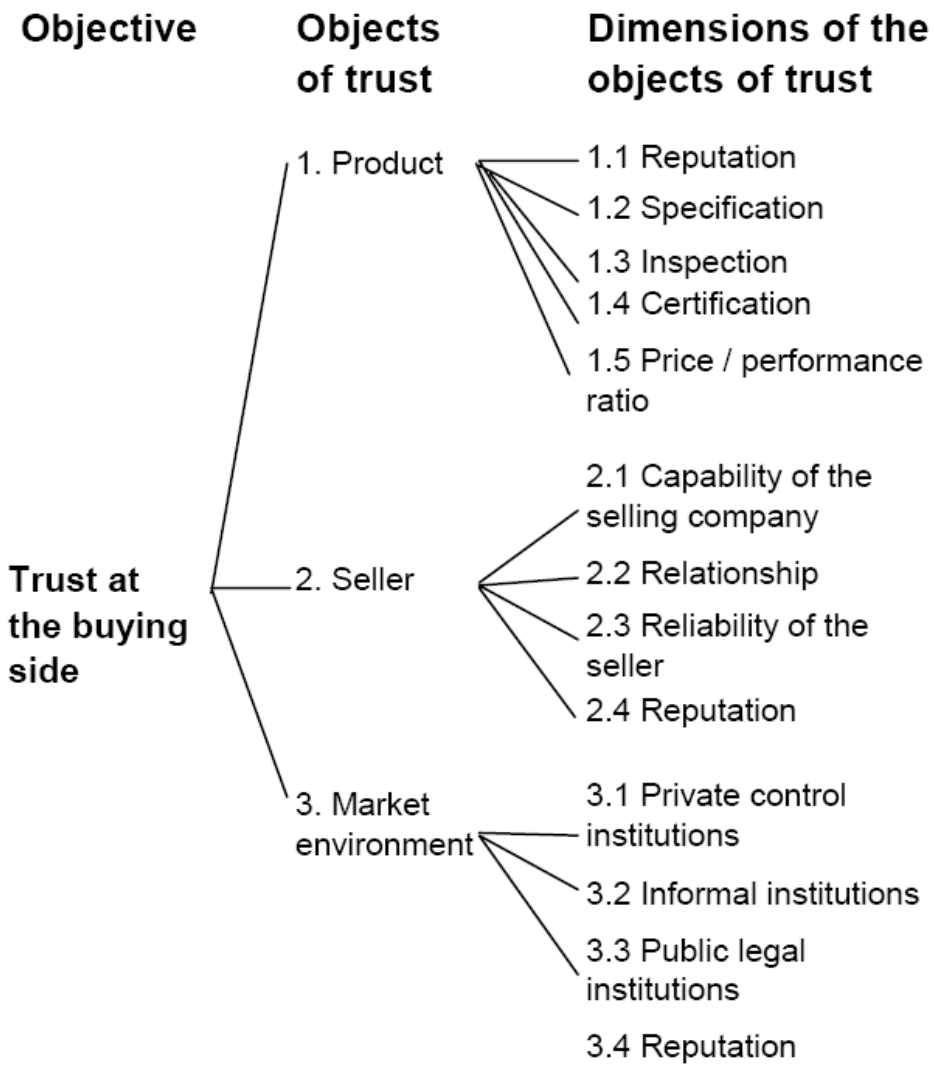

Figure 1: Top three levels of the typology of trust (Hofstede et al., forthcoming). 